\title{
Thermal and Pollutant-Emission Characteristics of Inverse Diffusion Biogas/Air Flame
}

\author{
Lei Lyu, Liang An, and Chun Wah Leung
}

\begin{abstract}
This paper presents the results of an experimental study on the thermal and pollutant-emission characteristics of a biogas-fired inverse diffusion flame (IDF) impinging vertically upwards on a horizontal copper plate. The IDF burner used in the experiment has a central air jet surrounded circumferentially by twelve outer fuel jets. The heat flux at the stagnation point and the radial distribution along the impingement plate were measured with a heat flux sensor while the temperatures were measured with thermocouples. The effects of Reynolds number, overall equivalence ratio, and nozzle-to-plate distance on the heat flux were investigated. The temperature and heat flux were calculated within a radial distance of $30 \mathrm{~mm}$ from the stagnation point of the flame, while air jet Reynolds numbers were chosen at 1000, 1500, 2000, 2500, 3000, 3500 and 4000. All the operation conditions were measured under both equivalence ratios of 2 and 3 with three different nozzle-to-plate distances of $60 \mathrm{~mm}, 90 \mathrm{~mm}$ and $120 \mathrm{~mm}$ (corresponding to the $\mathrm{H} / \mathrm{d}=10,15$ and 20). Besides, four different air pollutants emitted from the flame: $\mathrm{HC}, \mathrm{CO}_{2}, \mathrm{CO}$ and $\mathrm{NO}_{2}$ were measured. Heat flux and flame temperature distribution were affected by the equivalence ratio, Reynolds number and nozzle-to-plate distance. Higher equivalence ratio leads to occurrence of higher temperature and heat flux when the other conditions remain unchanged. The maximum temperature occurs at the stagnation point when the plate is above the flame, whereas the heat flux is low around the stagnation point when the flame is truncated by the plate. As for air pollutant emissions, $\mathrm{HC}$ is rare when the combustion is complete while $\mathrm{CO}$ increases with incomplete combustion. However, $\mathrm{CO}_{2}$ emission index is quite high which should be reduced in application.
\end{abstract}

Index Terms - Inverse diffusion flame, biogas fuel, thermal characteristics.

\section{INTRODUCTION}

With the rapid development of industry in recent years, energy sources especially sustainable green energy is urgently required because of the rapid depletion of global hydrocarbon fuels. Biogas, a gaseous fuel produced by the breakdown of organic matters such as municipal wastes or green wastes under the absence of oxygen, is conditionally using as a sustainable green fuel. The two major contents of biogas are methane $(\mathrm{CH} 4)$ and carbon dioxide $(\mathrm{CO} 2)$, with the fraction of carbon dioxide ranging from $30 \%$ to $60 \%$. Besides, there are also smaller amounts of nitrogen (N2),

Manuscript received December 20, 2017; revised May 13, 2018. This work was supported in part by the Mechanical Engineering Department, The Hong Kong Polytechnic University.

The authors are with the Mechanical Engineering Department, The Hong Kong Polytechnic University, Hong Kong (e-mail: lei.me.lyu@connect.polyu.hk, chun.wah.leung@polyu.edu.hk). hydrogen (H2) and hydrogen sulfide $\left(\mathrm{H}_{2} \mathrm{~S}\right)$ in it. Recently, burning biogas is not yet a mature technology applied extensively in either domestic or industrial applications because of its significant content of carbon dioxide leading to three major drawbacks: too narrow flame stability, too low heating value and too high carbon dioxide content in the combustion products.

Many attempts have been made to improve the characteristic of burning biogas. Zhen et al. [1] proposed that it is helpful to improve the stability and heating value of a biogas diffusion flame when adding a small amount of hydrogen to biogas. Zhen et al. [2] also compared the heat transfer behavior of diffusion flame and premixed flame when biogas with hydrogen addition was used as fuel. It was proven that the improvement of stability for both diffusion flame and premixed flame was achieved by the addition of hydrogen.

Flame types are also important for heat transfer characteristics. Premixed gas-fired flame and diffusion gas-fired flame are considered as two major flame types applied widely for both domestic and industry applications. However, their drawbacks are also significant. For premixed flame, it has low heat utilization rate, low flame temperature and narrow stable operation range. While for diffusion flame, it is not so suitable for low-Reynolds-number (such as domestic) applications and it has higher air-pollutant emission rates. Thus, it may be more suitable to apply their compromise: the gas-fired multi-fuel-jet inverse diffusion flame (MIDF) burner. The burner consists of a larger central circular air jet surrounding circumferentially by several smaller circular fuel jets. The high momentum central air jet entrains the outer fuel jets inward to produce a rapid mixing and hence ensure a turbulent flame facilitating a better reliability and higher heat transfer rate. At the same time, it draws the ambient air surrounding the fuel jets into the combustion zone to achieve a more complete burning and thus a cleaner combustion. Sze and Cheung [3] explored the temperature distribution and heat transfer characteristics of an inverse diffusion flame with circumferentially arranged fuel ports. They found that the radial heat flux distribution is highly affected by the nozzle-to-plate distance, Reynolds number and equivalence ratio.

Impingement heat transfer is mostly applied for domestic purpose. Dong et al. [4] and Kwok et al. [5] investigated the effect of Reynolds number, equivalence ratio and nozzle-to-plate distance on the temperature distribution and heat transfer of multiple impinging flame jets. $\mathrm{Ng}$ and Leung [6] also experimentally tested the heat transfer of an impinging inverse diffusion flame. Besides, Sze et al. [7] and Zhen et al. [8] studied the pollutant emission characteristics 
for inverse diffusion flame and premixed flame respectively, and concluded that pollutant emissions were affected by Reynolds number, equivalence ratio and nozzle-to-plate distance for both flame types.

\section{EXPERIMENTAL SETUP AND METHOD}

Fig. 1 and 2 schematically show the experimental setup for this study. For the study of thermal characteristics, we used heat flux sensor and thermocouples together with the test rig for measuring the local heat flux and temperature on the impingement plate produced by the flame. Heat flux sensor and thermocouples were replaced by gas emission analyzers to study the air-pollutant emissions. In the present study, we focused on four main kinds of air-pollutant emissions (CO, $\mathrm{CO}_{2}, \mathrm{HC}$ and $\mathrm{NO}_{\mathrm{X}}$ ). Both $\mathrm{CO}$ and $\mathrm{CO}_{2}$ were measured using Non-dispersed Infrared Sensor. HC was measured with Heated Flame Ionization Detector (HFID). For $\mathrm{NO}_{\mathrm{X}}$, the exhaust gases were analyzed using Heated Chemiluminiscence Analyzer after heating the samples to $333 \mathrm{~K}$. In this study, biogas was prepared by mixing methane $\left(\mathrm{CH}_{4}\right)$ and carbon dioxide $\left(\mathrm{CO}_{2}\right)$ according to the volumetric ratio of 50\%:50\%. The fuel supplies including $\mathrm{CH}_{4}$ and $\mathrm{CO}_{2}$ were controlled via calibrated valves and flow meters. All data were collected using a data logger. Every experiment was repeated three times and the average values were adopted as experimental results for reporting purpose.



Fig. 1. Experimental set-up for heat-transfer measurements.

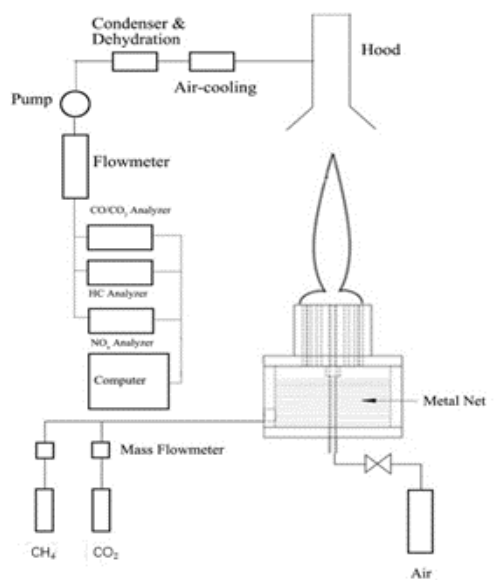

Fig. 2. Experimental set-up for pollutant-emissions measurement

\section{RESULTS AND DISCUSSIONS}

In the experiments, flame temperature distribution, impingement heat transfer distribution and pollutant-emissions were measured and shown in this paper.

\section{A. Flame Temperature}

In this section, the flame temperature distribution was measured. The H/d was set at 10, 15 and 20 obtaining at the nozzle-to-plate distance of $6 \mathrm{~mm}, 9 \mathrm{~mm}$ and $12 \mathrm{~mm}$, respectively. The measured points of temperature distribution were $0 \mathrm{~mm}, 5 \mathrm{~mm}, 10 \mathrm{~mm}, 15 \mathrm{~mm}, 20 \mathrm{~mm}, 25 \mathrm{~mm}$ and $30 \mathrm{~mm}$ along the radius direction from stagnation point. Fig. 3, 4, 5 and 6 show the temperature distribution under different operation conditions.

From Fig. 3, 4 and 5, effects of Reynolds number and H/d on temperature distribution are observed when the equivalence ratio is maintaining at 2 . Generally, temperature increases when the Reynolds number increases. There is one exception: the higher the Reynolds number is, the lower the flame temperature is at the center. It is because the air speed increases and the flame length will become longer, such that a too small $\mathrm{H} / \mathrm{d}$ provides insufficient room for complete combustion. To keep a relative high temperature, $\mathrm{H} / \mathrm{d}=15$ is a suitable distance for burning biogas when equivalence ratio $=2$. Fig. 6 shows the temperature distribution as the equivalence ratio increased from 2 to 3 while $\mathrm{H} / \mathrm{d}=10$ and Reynolds number is increased from 1000 to 4000.

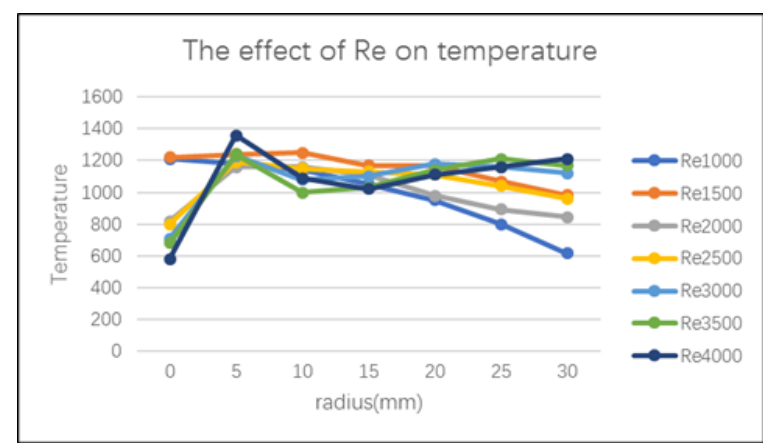

Fig. 3. Effect of $\mathrm{Re}$ on temperature when $\mathrm{H} / \mathrm{d}=10$ and equivalence ratio=2

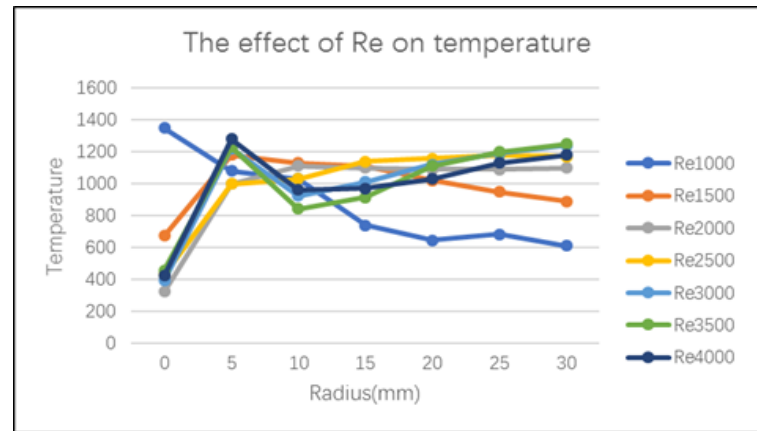

Fig. 4. Effect of $\mathrm{Re}$ on temperature when $\mathrm{H} / \mathrm{d}=15$ and equivalence ratio=2.

As observed from these four figures, effect of equivalence ratio on the temperature distribution is not very significant. Comparing the Fig. 3 and Fig. 6, which show the temperature distribution under $\mathrm{H} / \mathrm{d}=10$ at two different equivalence ratios. The maximum temperatures obtained at these two conditions are about $1400 \mathrm{~K}$. In general, temperature is low around the stagnation point when the flame is truncated by the plate and the temperature peak occurs at the stagnation point when the plate is placed above the flame. The radial location of maximum temperature appeared is obvious corresponding to the flame length. And the relationship between flame length and equivalence ratio and $\mathrm{Re}$ has been 
reported by Sze and Cheung [3].

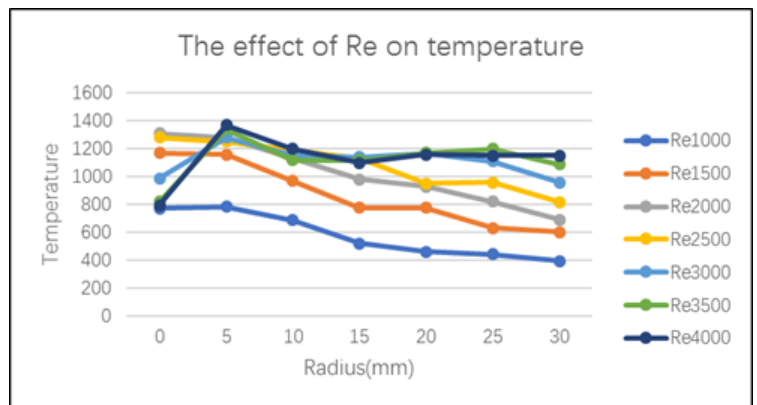

Fig. 5. Effect of Re on temperature when $\mathrm{H} / \mathrm{d}=20$ and equivalence ratio $=2$.

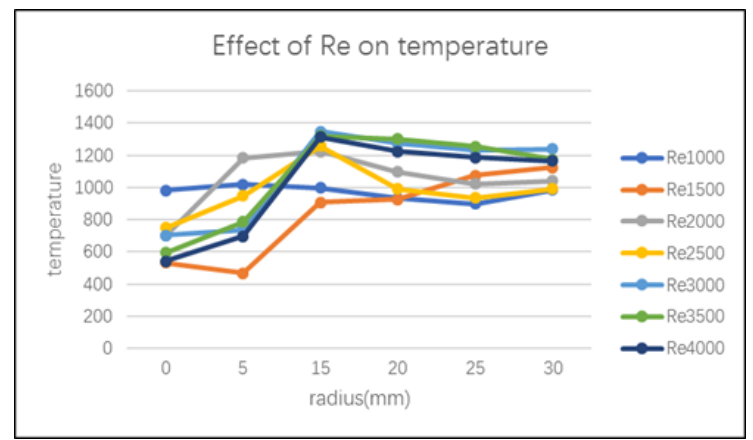

Fig. 6. Effect of Re on temperature when $\mathrm{H} / \mathrm{d}=10$ and equivalence ratio=3.

\section{B. Heat Flux Distribution}

In this section, the flame heat flux distribution was measured. Similarly, flame heat flux distribution was measured under different operation conditions from Reynolds number of 1000 to Reynolds number of 4000 with three different $\mathrm{H} / \mathrm{d}=10,15$, and 20. Fig. 7 to Fig. 10 conclude the experiment data to indicate the heat flux distribution.

For the impinging flames under a pre-set nozzle-to-plate distance, the heat flux was measured along the radial direction starting from the stagnation point. The impingement heat transfer can be influenced by many factors including Reynolds number, equivalence ratio and nozzle-to-plate distance. For instance, Fig. 9 shows the heat flux distribution under the nozzle-to-plate distance of $120 \mathrm{~mm}$ and the equivalence ratio of 2 . With the increase of Reynolds number, flame height increases so that the heat flux peak will occur at difference locations. As observed from this figure, it can be found heat flux is low around the stagnation point when the flame is truncated by the plate and heat flux peak occurs at the stagnation point when the plate is placed above the flame. In addition, the higher Reynolds number will lead to higher maximum heat flux value although they are obtained at different locations.

Some unburned air and fuel would be forced to the wall jet region and further react in the wall jet region when nozzle-to-plate distance is too small. With $\mathrm{H} / \mathrm{d}$ is increased, there is sufficient space for the intense combustion to occur near to the center of the impingement plate [6]. Comparing Fig. 7, 8 and 9, it can be concluded that the use of too small nozzle-to-plate distance will lead to the occurrence of low heat flux around the stagnation point so that a suitable distance is needed in application. Besides, appropriate Reynolds number is also crucial because higher Reynolds number will cause the lift phenomenon to occur more easily.
Equivalence ratio also has effect on the heat flux distribution. In general, higher equivalence ratio will lead to higher heat flux. Comparing Fig. 9 and 10, the heat fluxes are measured under the same conditions except equivalence ratio. Under the same Reynolds number, higher equivalence ratio will lead to the increase of flame height and heat transfer because the quantity of fuel flow is increasing. And for next stage, we are aim to measure thermal characteristics of burning lean-fuel, for example, heat flux and temperature under equivalence ratio 1 .

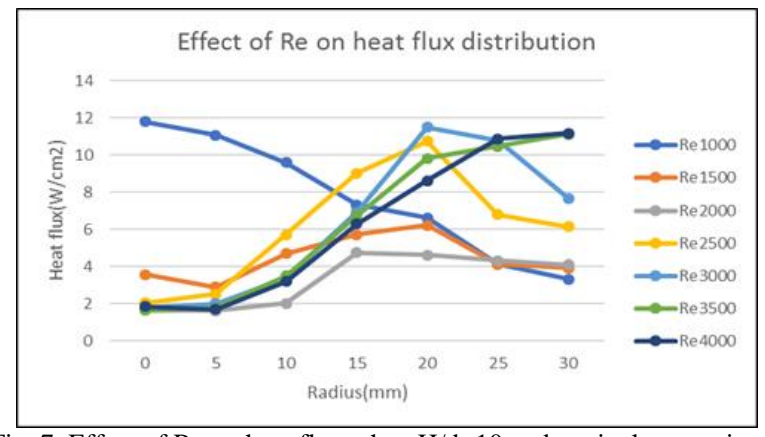

Fig. 7. Effect of $\mathrm{Re}$ on heat flux when $\mathrm{H} / \mathrm{d}=10$ and equivalence ratio=2

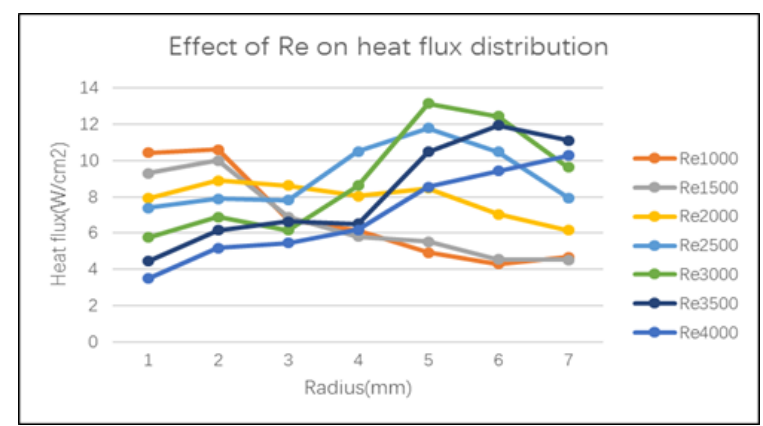

Fig. 8. Effect of $\operatorname{Re}$ on heat flux when $\mathrm{H} / \mathrm{d}=15$ and equivalence ratio=2.

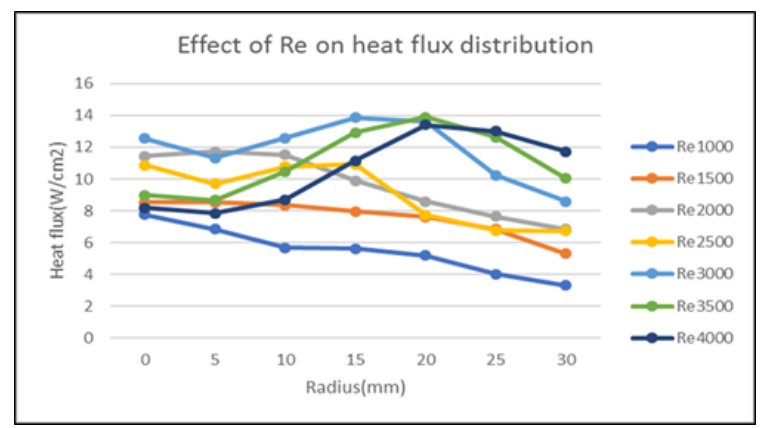

Fig. 9. Effect of $\operatorname{Re}$ on heat flux when $\mathrm{H} / \mathrm{d}=20$ and equivalence ratio=2.

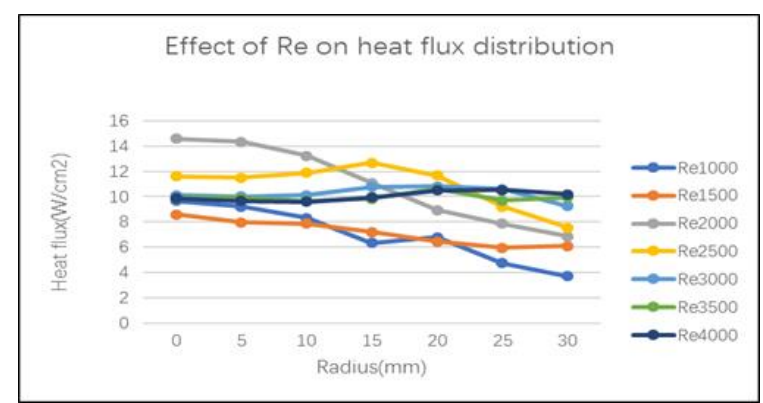

Fig. 10. Effect of $\operatorname{Re}$ on heat flux when $\mathrm{H} / \mathrm{d}=20$ and equivalence ratio=3.

\section{Pollutant-Emissions}

Four major pollutant emissions were measured including $\mathrm{HC}, \mathrm{NO}_{2}, \mathrm{CO}_{2}$ and $\mathrm{CO}$. The emission indices of these gases are reported in this section. These figures below show the 
effect of Reynolds number on pollutant emissions. Fig. 11 to Fig. 14 show their emission indices when equivalence ratio $=$ 2. For $\mathrm{HC}$ emissions (Fig. 11), when equivalence ratio $=2$, tendency of the EIHC decreases with the increasing of Reynolds number and the maximum EIHC is only 0.00005 which means $\mathrm{HC}$ emissions is negligible when equivalence ratio $=2$. However, when equivalence ratio $=3$, the EIHC has a huge increase (from 0.000025 to 0.00025 ) when Reynolds number is higher than 3500 . It is suggested that occurrence of the significant incomplete combustion is due to the flame lift phenomenon caused by the high Reynolds number flow.

Carbon dioxide $\left(\mathrm{CO}_{2}\right)$, a major contributor to the global warming, plays an important part in this project because biogas already contains very high percentage of $\mathrm{CO}_{2}$. From Fig. 12, $\mathrm{EICO}_{2}$ is not significantly affected by Reynolds number when equivalence ratio $=2$ : the maximum $\mathrm{EICO}_{2}$ is 1.465 while the minimum $\mathrm{EICO}_{2}$ is only 1.463 . However, a significant decrease is observed when Reynolds number is exceeding 3500 when equivalence ratio $=3$ which is caused by incomplete combustion of carbon (forming $\mathrm{CO}$ instead of $\mathrm{CO}_{2}$ ). It is echoed from the significant increase of $\mathrm{CO}$. Comparing Fig. 12 and Fig. 13, $\mathrm{EICO}_{2}$ at equivalence ratio $=$ 2 are larger than those $\mathrm{EICO}_{2}$ obtained at equivalence ratio $=$ 3 under the same operation conditions. The situation is opposite for EICO. For instance, when equivalence ratio $=3$ and Reynolds number $=3500$, the $\mathrm{EICO}_{2}$ decreases whereas the EICO increases. The decreased EICO is probably due to the fact that generally an increase in Reynolds number enhances the laminar burning velocity [8]. Thus, Fig. 12 and Fig. 13 show that $\mathrm{CO}$ emissions decreases while $\mathrm{CO}_{2}$ emissions increase, and the conversion rate from $\mathrm{CO}$ to $\mathrm{CO}_{2}$ is increasing with higher Reynolds number.

$\mathrm{NO}_{2}$ is also major emissions to be considered especially for domestic applications. From Fig. 14, the $\mathrm{EINO}_{2}$ is increased steadily from Reynolds number of 1000 to 3000 but it starts to decrease after the Reynolds number exceeds 3000. Further investigations will be carried out to explore the physics behind this scenario.

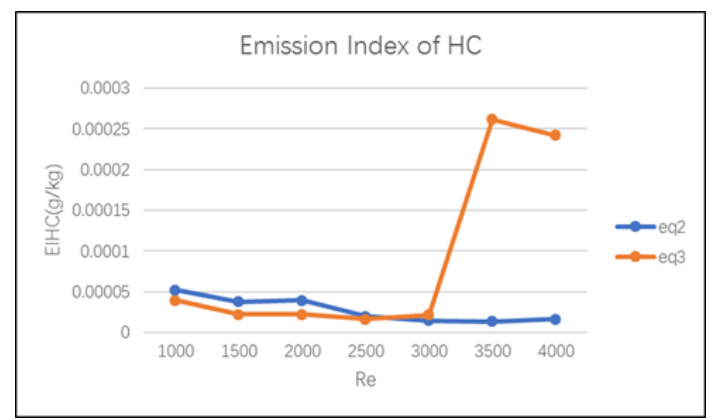

Fig. 11. Emission index of HC.

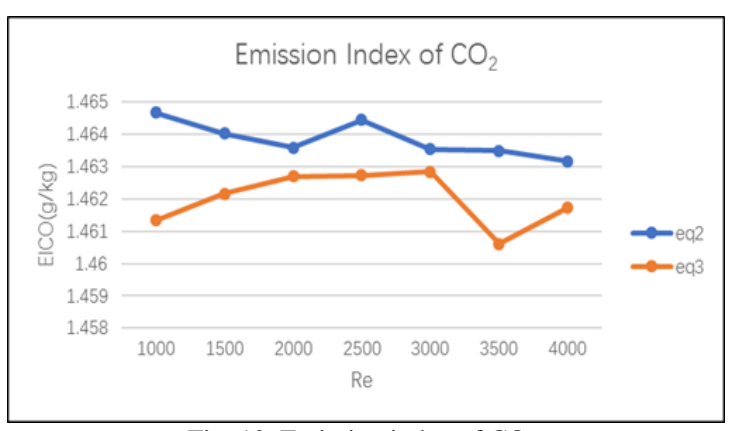

Fig. 12. Emission index of $\mathrm{CO}_{2}$.

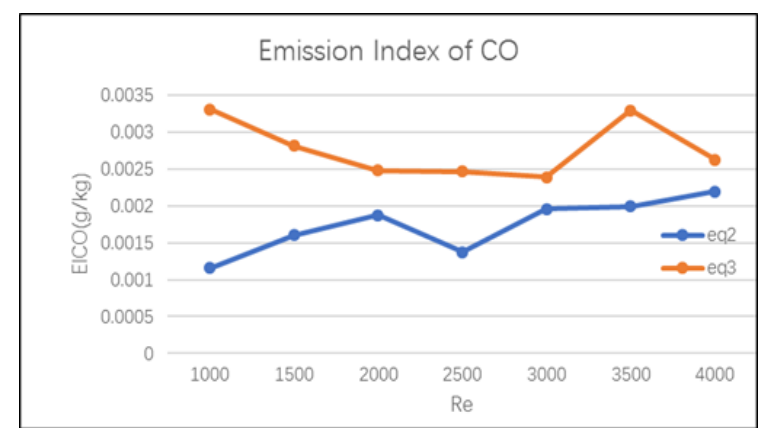

Fig. 13. Emission index of CO.

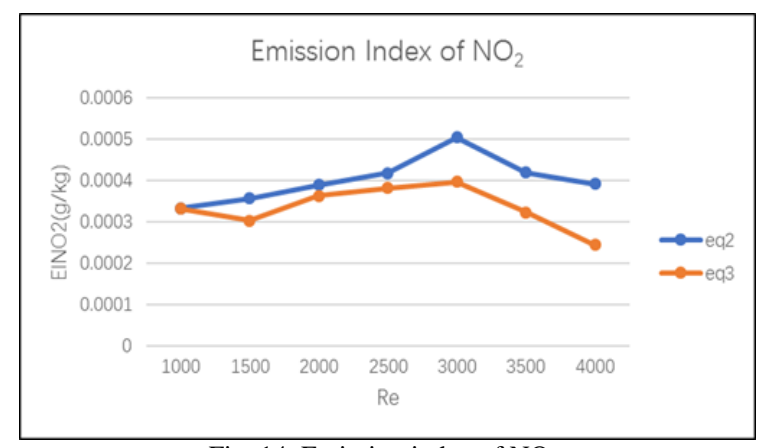

Fig. 14. Emission index of $\mathrm{NO}_{2}$.

\section{CONCLUSION}

This paper presents an experimental study focusing on the thermal and pollutant emission characteristics of biogas-fired impinging inverse diffusion flames. The main components of biogas under investigated are $50 \% \mathrm{CH}_{4}$ and $50 \% \mathrm{CO}_{2}$ by volume. Heat flux and flame temperature distributions on the impingement plate are included as thermal characteristics whereas $\mathrm{CO}, \mathrm{CO}_{2}, \mathrm{HC}$ and $\mathrm{NO}_{\mathrm{X}}$ are the pollutant emissions from the flame to be examined. Effects of equivalence ratio and Reynolds number of the air/fuel jets, and nozzle-to-plate distance of the burner system on these characteristics are explored.

When equivalence ratio and nozzle-to-plate distance are kept constant, temperature and heat flux distributions increase with the increasing Reynolds number. When Reynolds number and nozzle-to-plate distance are kept constant, use of higher equivalence ratio will result in higher temperature and heat flux distributions on the impingement plate.

It is concluded that both the temperature and heat flux are low at the region around the stagnation point when the flame is truncated by the plate, but the temperature and heat flux peaks occur at the stagnation point when the plate is placed above the flame. It emphasizes the importance in choosing the suitable nozzle-to-plate distance for the burner system in practice.

$\mathrm{HC}$ emissions are insignificant when the combustion is complete while $\mathrm{CO}$ emissions increase with the enhancement of incomplete combustion. $\mathrm{CO}_{2}$ emission index is rather high when biogas is used as fuel which should be reduced in applications. Considering the operation range, thermal and pollutant emission characteristics of the inverse diffusion biogas/air flame (especially low heating value and rather high $\mathrm{CO}_{2}$ emissions), comparing with premixed and diffusion flames, it is still a worthwhile technology to be further explored. 


\section{ACKNOWLEDGMENT}

The authors wish to thank the Hong Kong Polytechnic University for financial support of the present study.

\section{REFERENCES}

[1] H. S. Zhen, C. W. Leung, and C. S. Cheung, "Effects of hydrogen addition on the characteristics of a biogas diffusion flame," Int. J. Hydrogen Energy, vol. 38, no. 16, pp. 6874-6881, 2013.

[2] H. S. Zhen, C. W. Leung, and C. S. Cheung, "A comparison of the heat transfer behaviours of biogas-H2 diffusion and premixed flames," Int. J. Hydrogen Energy, vol. 39, no. 2, pp. 1137-1144, 2014.

[3] L. K. Sze, C. S. Cheung, and C. W. Leung, "Temperature distribution and heat transfer characteristics of an inverse diffusion flame with circumferentially arranged fuel ports," International J. Heat and Mass Transfer, vol. 47, pp. 3119-3129, 2004.

[4] L. L. Dong, C. S. Cheung, and C. W. Leung, "Heat transfer from an impinging premixed butane/air slot flame jet," Int. J. Heat and Mass Transfer, vol. 45, pp. 979-992, 2002.

[5] L. C. Kwok, C. W. Leung, and C. S. Cheung, "Heat transfer characteristics of slot and round premixed impinging flame jets," Exp. Heat Transfer, vol. 16, pp. 111-137, 2003.

[6] T. K. Ng, C. W. Leung, and C. S. Cheung, "Experimental investigation on heat transfer of an impinging inverse diffusion flame," International J. Heat and Mass Transfer, vol. 50, pp. 3366-3375, 2007.

[7] L. K. Sze, C. S. Cheung, and C. W. Leung, "Appearance, temperature, and $\mathrm{NO}_{\mathrm{X}}$ emission of two inverse diffusion flames with different port design," Combustion and Flame, vol. 144, no. 1-2, pp. 237-248, 2006.

[8] H. S. Zhen, Z. L. Wei, C. W. Leung, C. S. Cheung, and Z. H. Huang, "Emission of impinging biogas/air premixed flame with hydrogen enrichment," Int. J. Hydrogen Energy, vol. 41, no. 3, pp. 2087-2095, 2016.

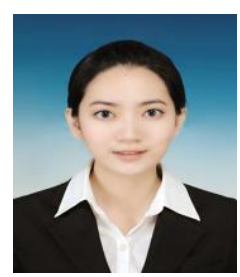

Lei Lyu was born at Shan Xi Province China. She received her bachelor degree in thermal and power engineering from the University of Shanghai for Science and Technology, Shanghai, China. And she is studying her master degree in the Department of Mechanical Engineering of The Hong Kong Polytechnic University, Hong Kong. She is a postgraduate student in the Hong Kong Polytechnic University and her research field is fuel, flame and combustion now.

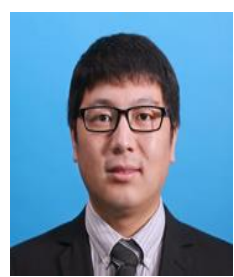

Liang An received his $\mathrm{PhD}$ degree in mechanical engineering from the Hong Kong University of Science and Technology. He is currently an assistant professor in the Department of Mechanical Engineering at the Hong Kong Polytechnic University. He has authored and co-authored more than 70 journal papers. His research interests include advanced energy conversion and storage technologies, such as fuel cells and batteries.

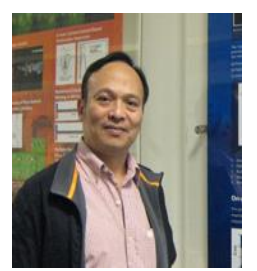

Chun Wah Leung obtained his BSc and MSc degree programmes in mechanical engineering, in the University of Sunderland and the Cranfield University in 1978 and 1985 respectively, and completed his $\mathrm{PhD}$ research programme in the University of Sunderland in collaboration with the Cranfield University in 1989.

He joined the Hong Kong Polytechnic University in 1980 as a lecturer, and promoted to be a professor in 1999. He was the associate head of the Department for 9 years. Retired in late 2017, he has been appointed as adjunct professor in the Department of Mechanical Engineering. His research field is heat transfer; fuel and combustion; internal combustion engine emissions and their control. 